\title{
Air pollution forecasts and results-oriented tracking
}

\author{
John Bachmann
}

Received: 13 October 2008 / Accepted: 22 December 2008 / Published online: 27 January 2009

(C) The Author(s) 2009. This article is published with open access at Springerlink.com

\begin{abstract}
This paper provides a brief overview of recent EPA forecasts of air quality and emissions related to ozone and particle pollution. It is intended to supplement conference papers on air quality (White 2007) and benefits estimates by highlighting the potential utility of national, regional, and local forecasts in developing and implementing health and environmental quality tracking programs. As Hubbell and Fann (2007) note, such forecasts are of particular importance in evaluating the feasibility and design of programs intended to assess the benefits of airrelated control or mitigation programs. Tracking programs may focus on overall air quality improvements or on reductions from particular source categories of interest.
\end{abstract}

Keywords Air pollution tracking - Air pollution benefits . Air pollution forecasts $\cdot$ Accountability

\section{The past as prelude}

Over the past three decades of the Clean Air Act, EPA state, local, and tribal agencies, other major stakeholders in the process, including the private sector, have worked to implement programs aimed at reducing emissions of those pollutants that contribute to poor air quality (Fig. 1; Bachmann 2007). The national-level trends in criteria pollutants and selected hazardous air pollutants (HAP) shown in Fig. 2 (EPA 2008a) indicate the progress in air quality resulting from these programs. Of the six pollutants for which national ambient air quality standards (NAAQS)

J. Bachmann $(\bowtie)$

Vision Air Consulting,

Chapel Hill, NC, USA

e-mail: JohnBachmann@bellsouth.net exist, only two-ozone and PM2.5-remain persistent, widespread problems with concentrations above, or close to, the NAAQS. As is more evident in below, this situation is forecast to continue, particularly with the recent tightening of the PM and ozone NAAQS.

\section{National emissions and air quality forecasts}

EPA recently promulgated a number of federal regulations to reduce multiple air pollutants. In 2006, EPA implemented the "Clean Air Rules," which included the Clean Air Interstate Rule (CAIR), the Clean Air Mercury Rule (CAMR), and the Clean Air Visibility Rule. These rules target emissions of $\mathrm{NO}_{x}, \mathrm{SO}_{2}$, and mercury from power plants. In addition, EPA promulgated the Clean Air Nonroad Diesel Rule in 2004 aimed at reducing $\mathrm{PM}, \mathrm{NO}_{x}$, and $\mathrm{SO}_{x}$ from construction, agricultural, and industrial dieselpowered equipment. EPA has produced emissions and air quality forecasts for these as well as more recent programs (EPA 2005).

Unfortunately, recent lawsuits have led to a suspension of programs directed at the power sector (CAIR, CAMR). The CAIR program has been viewed as so important that significant legislative, legal, and policy activities are underway to reinstate or replace it with a comparable program. As of this writing, however, it is not clear when and how programs providing equivalent or even more reductions will be put into place, making it almost certain that the forecast $\mathrm{SO}_{x}$ and $\mathrm{NO}_{x}$ reductions will be delayed (Bachmann and Wierman 2008). Accordingly, the projections in the rest of this paper illustrate reductions that may occur 1 to 2 years later than suggested.

Figure 3 (EPA 2008a) shows the projected changes in pollutant emissions between 2001 and 2020, including the 


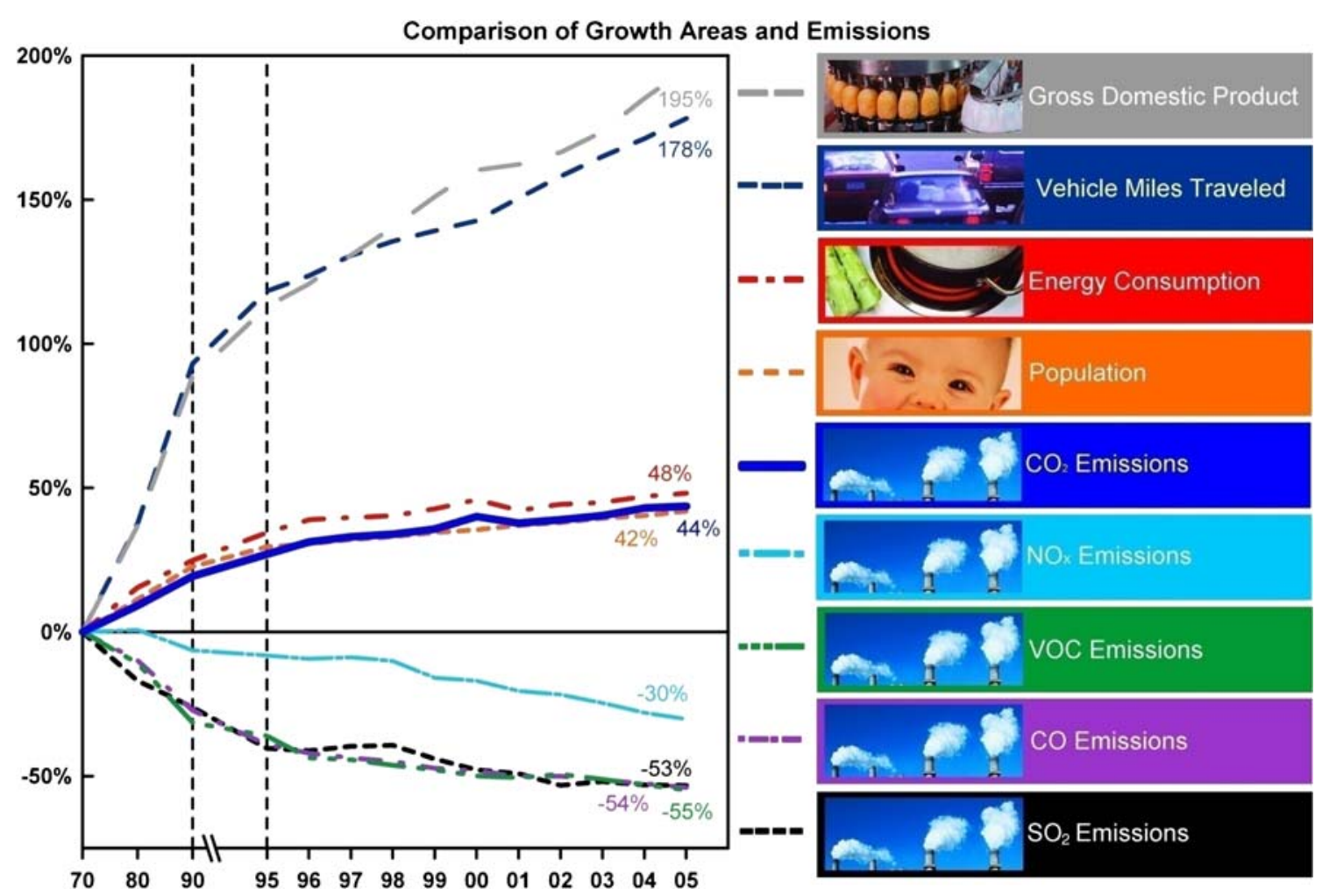

Fig. 1 National Emissions Trends. Clean Air Act programs effected substantial emissions of targeted pollutants as compared to CO2, which was not
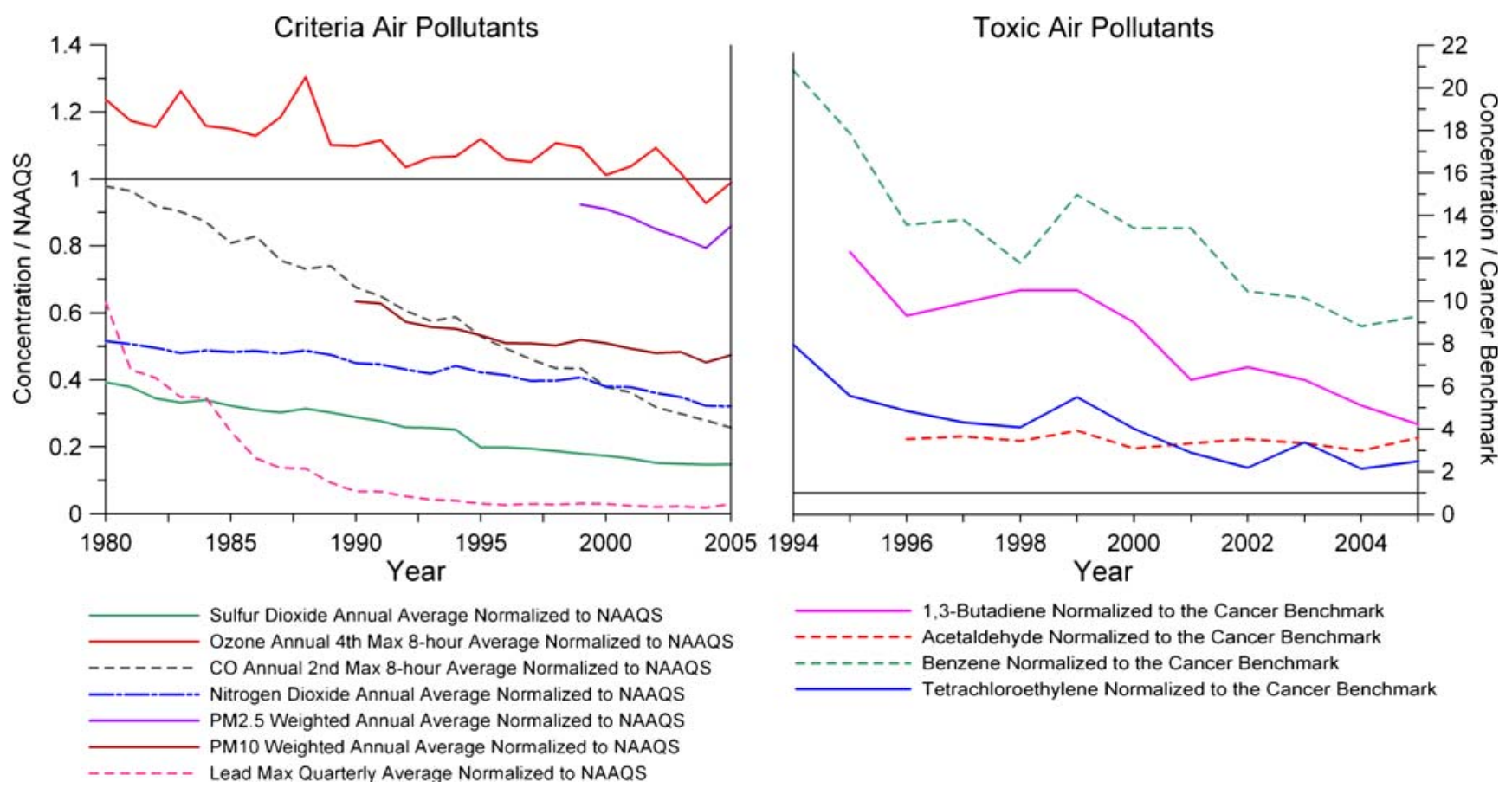

Fig. 2 National-level trends in criteria and selected HAPs relative to the NAAQS and cancer benchmarks Criteria pollutant programs contributed to reduction of specific toxic materials, including some automotive VOCs 


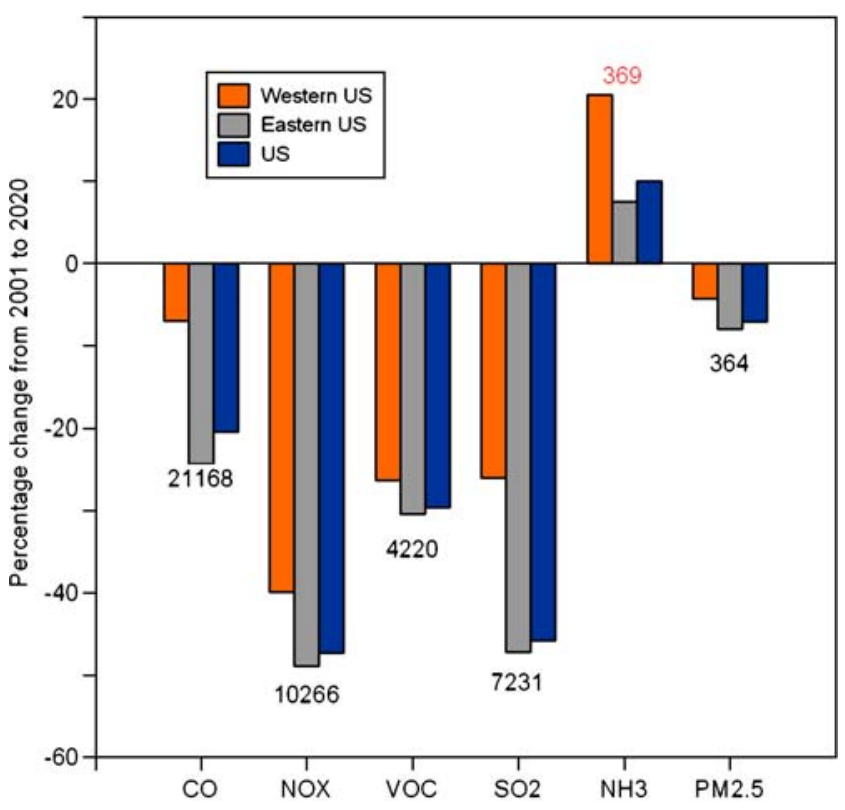

Fig. 3 Projected changes in pollutant emissions between 2001 and 2020 if the Clean Air Rules and other baseline programs were implemented (see text). Numbers near each set of bars is the reduction or increase in thousands of tons

reductions that would result from implementing the original Clean Air Rules. With the exception of $\mathrm{NH}_{3}$, all pollutants are expected to decline over this timeframe with significant reductions between $30 \%$ and $50 \%$ for $\mathrm{NO}_{x}, \mathrm{SO}_{2}$, and VOCs. These declines demonstrate the effectiveness of CAA programs; however, the table also shows the large remaining emissions across the eastern and western US in 2020.
Figure 4 (EPA 2008a) shows recent and projected improvements in PM and ozone air quality resulting from the Clean Air Rules and other baseline emissions reductions programs. Recent significant improvements observed in these pollutants between 1999 and 2001 and 2003-2005 are primarily due to the acid rain program, $\mathrm{NO}_{x}$ SIP Call, and mobile source programs implemented during this period. The pollutant emission reductions forecast by 2020 from these programs would result in still fewer projected non-attainment areas for ozone and $\mathrm{PM}_{2.5}$. Ozone and $\mathrm{PM}_{2.5}$ exceedances are projected to continue in Southern and Central California. Ozone is a persistent issue for the Northeast corridor and Houston area, while $\mathrm{PM}_{2.5}$ issues will continue in midwestern cities such as Chicago, IL; Detroit, MI; and Cleveland, $\mathrm{OH}$; as well as Birmingham, AL. These maps overstate non-attainment to the extent that local or subregional programs are adopted to attain the standards. On the other hand, these figures do not include the 2006 $\mathrm{PM}_{2.5}$ standard or the revised 8-h ozone standard of $0.75 \mathrm{ppm}$. Figure 5 (EPA 2006, 2007b) shows areas with monitors not meeting the most recently revised $\mathrm{O}_{3}$ and $\mathrm{PM}_{2.5}$ NAAQS.

\section{Some implications for tracking and accountability}

Recognizing their inherent limitations, these national level forecasts can provide some indication of the extent of potential emissions and air quality improvements in particular areas expected over the next decade. This might provide some
Fig. 4 Recent and projected $\mathrm{O}_{3}$ and $\mathrm{PM}_{2.5}$ air quality, 1999 2020 (relative to 1997 NAAQS). a Ozone, 0.075 ppm, 8-h; b PM, Yellow-daily (35 vg/m3), orange-annual(15 vg/m3), redboth
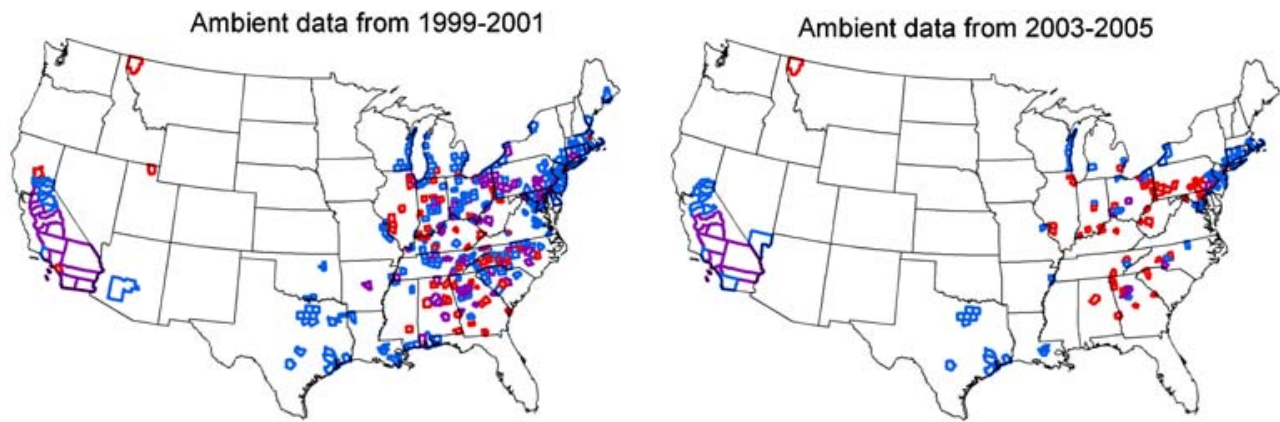

Model Predicted Air Quality in 2020

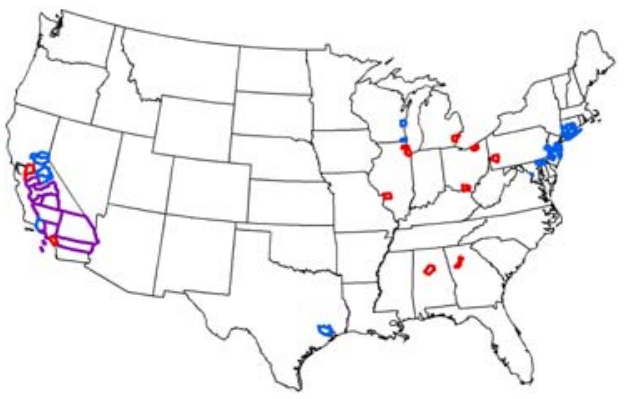

County Ambient Air Quality

PM2.5 above NAAQS

Ozone above NAAQS

Ozone and PM2.5 above NAAQS 
Fig. 5 Counties with monitors projected to violate revised NAAQS for $\mathbf{a}$ and $\mathbf{b}$ PM2.5 (2004-2006 data) a

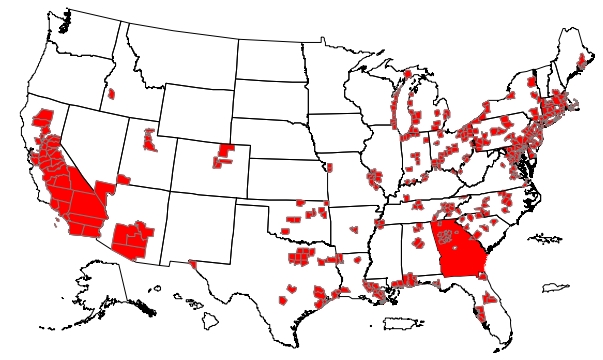

Ozone, 0.075ppm, 8- hour b

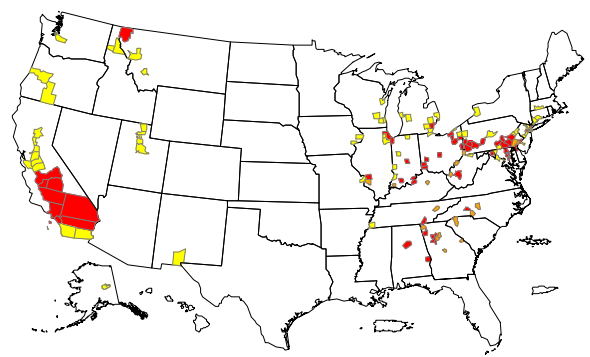

PM, Yellow-daily (35 vg/m3), orange annual(15 vg/m3); Red both guidance to those seeking to track areas with the most significant reductions. In particular, those areas forecast to have continued non-attainment for ozone and PM in 2020 are those with a responsibility to develop additional control programs that attain the relevant standards. More area-specific forecasts will be produced by areas as they develop their control strategies and implementation plans.

These forecasts can be broken according to specific source categories and particular areas. An examination of the historical trends and the time course of the emissions reductions indicate we are currently in a period with the highest rate of anticipated emissions reductions. Figure 6 (Sommers 2007; EPA 2007a) shows forecasted national changes in mobile source emissions from on- and off-road vehicles for direct $\mathrm{PM}$ and $\mathrm{NO}_{x}$. The later year projections are more uncertain, but it appears that tracking programs over the next several years have a better chance for detecting trends.

Trends, timing, and relative importance of local sources will, of course, vary with location. In addition, uncertainties

a

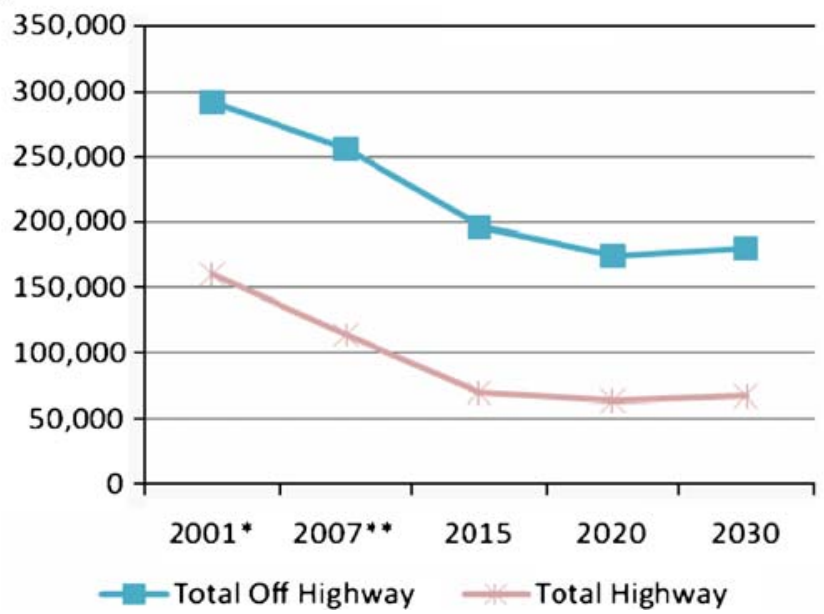

in these emissions inventories may be significant, especially for mobile source PM emissions. The relative change forecast for mobile emissions is large for both particles and gases. Given increasing evidence of increased health risk with proximity to traffic, it would be of some interest to examine the feasibility of detecting trends in areas with greater than average reductions forecast for direct PM and pollutant gases. The national forecasts suggest that such tracking programs should begin soon, if they are not already underway, as we are already moving into a period of maximum change for both on and off-road sources. The absolute PM reductions forecast appear small but recent comparisons of emissions data with air quality data suggest the contribution of direct mobile source PM is substantially larger than implied by the emissions data (EPA 2006). While overall mass will decline, the trends for near-roadway ultrafine particles are less clear. Reductions in fine particle mass can increase ultrafine particles, but some technologies reduce both and the reduction in roadway $\mathrm{SO}_{2}$ and $\mathrm{NO}_{x}$ will also affect secondary ultrafine particle production. b

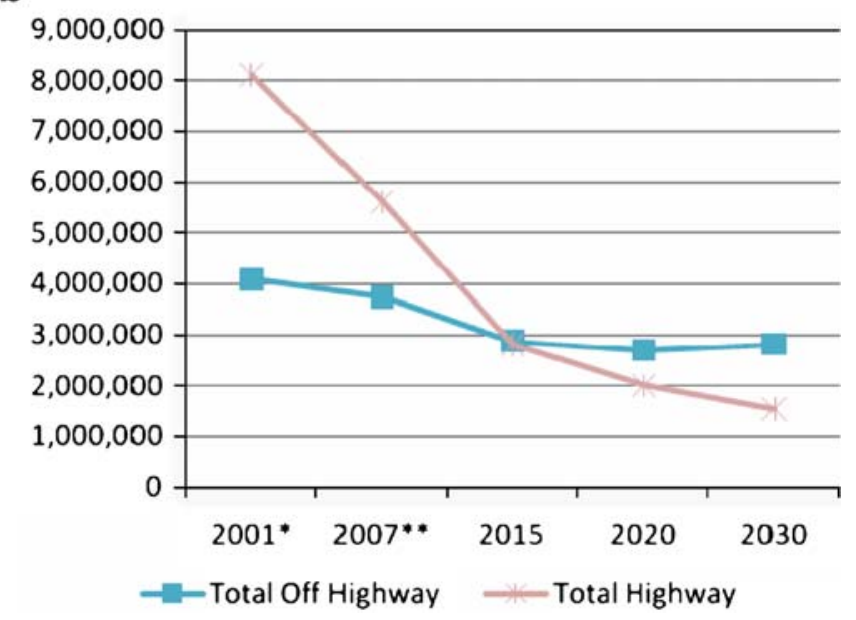

Fig. 6 Forecast mobile emissions for a direct PM2.5 and $\mathbf{b} \mathrm{NO}_{x}$ in tons. The rate of observed or projected reductions is larger between 2001 and 2015 than in later years. Similar patterns are seen for mobile VOC and stationary $\mathrm{NO}_{x} / \mathrm{SO}_{2}$ 
Because stationary sources of fine particles are also declining at the same time and the overall change from year to year is modest, those interested in near roadway trends might want to consider targeting tracking programs to areas with the best "signal to noise" for such sources. A number of areas are implementing or planning interventions that reduce existing diesel emissions faster than the national new source regulations. They involve school bus and fleet retrofits and programs to address existing marine emissions. Examples include the West Coast Diesel Emissions Reductions Collaborative, the Midwest Clean Diesel Initiative, and the Rocky Mountain Clean Diesel Collaborative (EPA 2008b). Areas affected by these programs should have faster than average improvements in diesel PM and related gas emissions. The patterns of emissions and reductions will vary in port cities, such as Seattle, as compared to areas with programs that address only school buses and fleets. It may be easier to detect the effect of heavy-duty diesel emissions in such areas, and a comparison of areas with and without interventions, as well as comparing eastern (with additional regional PM reductions) to western areas. From a within-city point of view, there may be advantages for a cross-sectional study in a port city with major near road and near port gradients in exposures to marine and terrestrial emissions.

\section{Conclusions}

The design and deployment of both routine and special programs to track trends in air pollution and health effects would benefit from an examination of relevant air quality and emissions trends and forecasts that assess both regulations and voluntary air quality management programs. Given recent literature on the potential health effects of near roadway exposures, special tracking studies should look for planned interventions that are expected to markedly reduce population exposures to both on and offroad diesel emissions.
Acknowledgements I appreciate the access to relevant spreadsheets and figures provided by EPA's Norm Possiel (Office of Air Quality Planning and Standards) and Joseph Somers (Office of Transportation and Air Quality).

Open Access This article is distributed under the terms of the Creative Commons Attribution Noncommercial License which permits any noncommercial use, distribution, and reproduction in any medium, provided the original author(s) and source are credited.

\section{References}

Bachmann J (2007) Will the circle be unbroken: a history of the us national ambient air quality standards. J Air Waste Manag Assoc 57(6):652-697 EM June 2007, 27-34

Bachmann J, Wierman S (2008) Urgent CAIR Needed. EM. December 2008, 6-10. See also http://www.epa.gov/cair/pdfs/ 05-1244-1127017.pdf

Hubbell B, Fann N (2007) Methodological Considerations in Developing Local Scale Health Impact Estimates Using National/Regional Data. HEI Tracking Workshop

US Environmental Protection Agency (2005) Regulatory Impact Analysis for the Clean Air Interstate Rule. EPA 452/-03-001. Prepared by Office of Air and Radiation. Available at: http:// www.epa.gov/interstateairquality/tsd0175.pdf; see also http:// www.epa.gov/clean air2004)

US Environmental Protection Agency (2006) Regulatory Impact Analysis of the 2006 National Ambient Air Quality Standards for Particle Pollution. Office of Air Quality Planning and Standards, October

US Environmental Protection Agency (2007a) Technical Support Document for the Proposed Locomotive/Marine Rule: Air Quality Modeling. Office of Air Quality Planning and Standards. EPA-452/R-07-004, March

US Environmental Protection Agency (2007b) Regulatory Impact Analysis of the Proposed Revisions to the National Ambient Air Quality Standards for Ground-Level Ozone. Office of Air Quality Planning and Standards. EPA-452/R-07-008, July

US Environmental Protection Agency (2008a) The Multipollutant Report. Technical Concepts and Examples. Office of Air Quality Planning and Standards, July. http://www.epa.gov/airtrends/ specialstudies/20080702_multipoll.pdf

US Environmental Protection Agency (2008b) National Clean Diesel Campaign. http://epa.gov/otaq/diesel/index.htm (January 3, 2008)

White W (2007) Considerations in the use of ozone and PM2.5 data in exposure assessment. HEI Tracking Workshop 